\title{
Integrated Optimal Control of Battery Energy Storage Management System for Energy Management and PV Capacity Firming
}

\author{
Sherif Abdelrazek, Sukumar Kamalasadan, Johan Enslin \\ Department of Electrical and Computer Engineering \\ University of North Carolina at Charlotte \\ Charlotte, NC, USA
}

\author{
Tom Fenimore \\ Emerging Technology Office \\ Duke Energy Corporation \\ Charlotte, NC, USA
}

\begin{abstract}
In this paper and integrated battery energy management algorithm for optimal control of power and energy of a medium voltage feeder is discussed. The proposed unique control algorithm enhances coordination of two main storage applications, viz., Photo-Voltaic Capacity Firming (PVCF) and electric Energy Time Shift (ETS). Optimization of control parameters and set points are considered for management between the mentioned applications. Practical implementation results on a utility feeder are discussed.
\end{abstract}

Index Terms-Batteries, Energy storage, Battery Management Systems, Capacity Firming, Message Bus, Renewables Integration

\section{INTRODUCTION}

As modern electrical grids, especially, in the distribution level, evolve to incorporate extensive asynchronous renewable energy systems, the need and requirement for voltage profile and transient stability enhancements becomes ever more important. Utilization of energy storage technologies with high ramp rate capabilities and decrementing cost to counter act rapid power swings which are characteristic to renewable energy systems becomes essential to maintain grid stability. Battery Energy Storage Systems (BESSs) serve as a perfect fit for ramp rate limiting and arbitrage applications [1]-[10]. However, there is a concurrent need to quantify the "value" of these storage applications based on the various services they provide to the grid, individually and in multiple or "stacked" manner, where a single storage system has the potential to capture several revenue streams to achieve economic viability. This is important now and in future as the cost of storage systems decline to economically attractive levels [11].

Reference [12] discusses tools for evaluating Battery Energy Management System (BESS) multiple functions value streams based on various applications and battery technologies. Such tools provide ability to evaluate applications and technologies that has greater value for grid level energy storage. However, it is important to develop multiple control functions for storage management systems considering grid level value and economic benefits for a given storage technology [13-19]. Such control architecture should interact with distribution networks and provide command signals to storage management systems for the appropriate set

Authors would like to thank Duke Energy Corporation for the Duke Energy Grant awarded to the second author for this study. points and applications that provide maximum benefit at a given time.

Earlier several works has focused on PV capacity firming. Even though there is no unique way to smooth the PV output, $[19,20]$ focus on a moving average based ramp-rate control. Also an exponential moving average method has been utilized in [21] for controlling the battery. Also a dynamic filtering controller and dynamic rate limiter approach is used in [20] for smoothing of PV and wind power generation fluctuations. Reference [16] proposes a modified ramp rate control that can be used based on the time instant of the PV active power output. However, most of these works propose some incremental changes to PV smoothing and does not consider multiple functions for the storage that can be used simultaneously at given point of time.

In this paper, a new method for integrating BESS multiple functionalities is discussed. The proposed method works with the Storage Management System (SMS) to enhance its active power capabilities while utilizing an innovative communication scheme to convey system data to the devised controller and return controller output to the BESS. During the process, the controller evaluates the need and requirement of the distribution feeder. This paper is organized as follows; the first section includes the test system topology. Second, the proposed energy management system control methodology and framework is discussed. Third, the communication and control architecture details implemented are examined. Implementation results are presented in the fourth section showing practical results of implementation of the devised algorithm running on the described feeder utilizing the discussed communication technique. Finally, conclusions are derived from the shown practical results.

\section{SYSTEM TOPOLOGY}

\section{A. Distribution Feeder}

The distribution feeder shown in Fig. 1 is an aggregated model of a practical 720 node, $12.475 \mathrm{kV}$ distribution feeder which has a $1.25 \mathrm{MVA} / 750 \mathrm{kWh}$ BESS connected in conjunction with a $1 \mathrm{MW}$ PV station at the same Point of Common Coupling (PCC) shown. The PCC is practically located at the end of the distribution feeder. For modeling purpose, a fictitious bus is assumed at the middle of the distribution feeder to represent feeder load. The circuit impedances shown are aggregations of total feeder impedances between the substation and PCC. These 
impedance values are calculated using practical feeder data and with model validation and tuning.

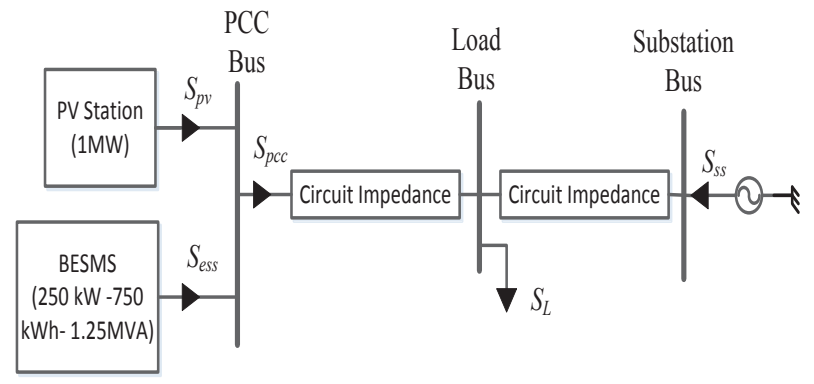

Fig. 1 Distribution feeder model

\section{B. Battery Energy Storage \& Management System (BESMS)}

As shown in Fig. 2, The BESMS consists of the SMS and BESS. The BESS is comprised of a lithium polymer battery and a Battery Management System (BMS). The lithium polymer battery model was developed and validated based on methods similar to that in [13].

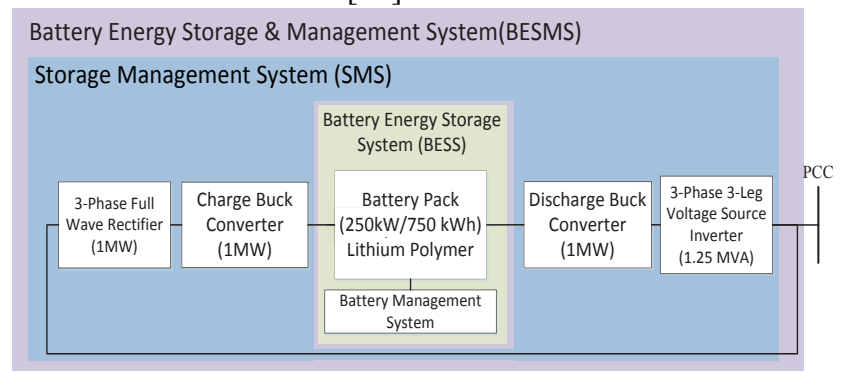

Fig. 2 Battery Energy Storage and Management System model

\section{i. Storage Management System}

The SMS topology described allows charge and discharge operations of the BESS regardless of the reactive power dispatch state. The discharge path consists of a $1 \mathrm{MW}$ DC-DC buck converter and a $1.25 \mathrm{MVA}$ three phase voltage source inverter. The charge path consists of an uncontrolled three phase full wave rectifier connected to a DC-DC buck converter which is responsible for the rate of charge of the battery. The operation is modeled using EMTP $^{\circledR}$ software.

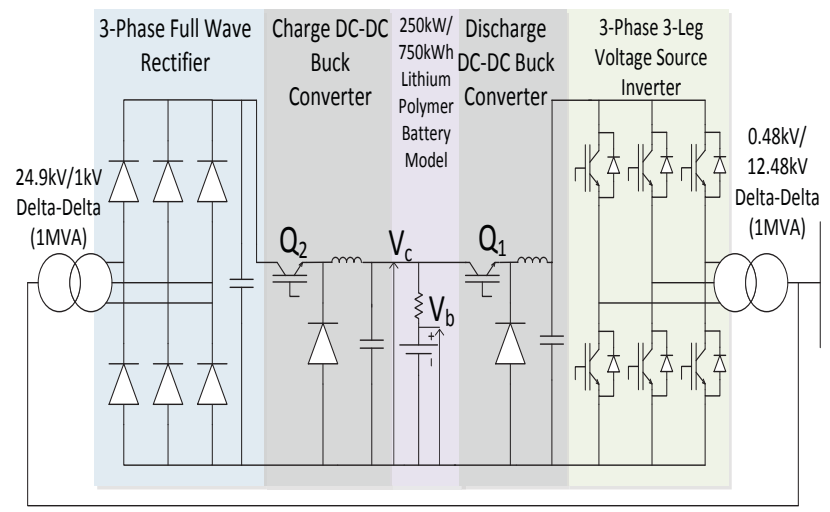

Fig. 3 SMS Electro Magnetic Transient Program (EMTP) simulation model

During the battery discharge cycle, switch $\left(\mathrm{Q}_{1}\right)$ shown in Fig. 3 is controlled to hold the DC link voltage to a set value.
Switch $\left(\mathrm{Q}_{2}\right)$ remains open during discharge operation. Inverter switches are controlled by Pulse Width Modulation (PWM). Modulation index is set according to the reactive power required to be supplied or consumed from the feeder $\left(Q_{\text {set }}(t)\right)$. The phase of the PWM reference signal controls the active power output and is set by the positive values of the active power reference signal $\left(P_{\text {set }}(t)\right)$.

During charge cycle, power is provided to the battery through the 3-phase full wave rectifier and the second buck converter. The rectifier sets the voltage at the charge DC link. Switch $\left(\mathrm{Q}_{2}\right)$ shown in Fig. 3 is controlled to buck the rectified voltage at the DC link to the required voltage output value for the required battery charge rate. The voltage $\left(V_{c}\right)$ required to charge the battery is calculated from the desired charge rate, which is represented by negative values of the active power reference signal $\left(P_{\text {set }}(t)\right)$.

\section{i. Battery Energy Storage System}

The studied practical BESS has an energy storing capacity of $750 \mathrm{kWh}$ and a power capacity of $250 \mathrm{~kW}$. The BESS is mainly comprised of the battery pack and the Battery Management System (BMS) responsible for management, protection and operation of the battery pack's cells, modules and racks.

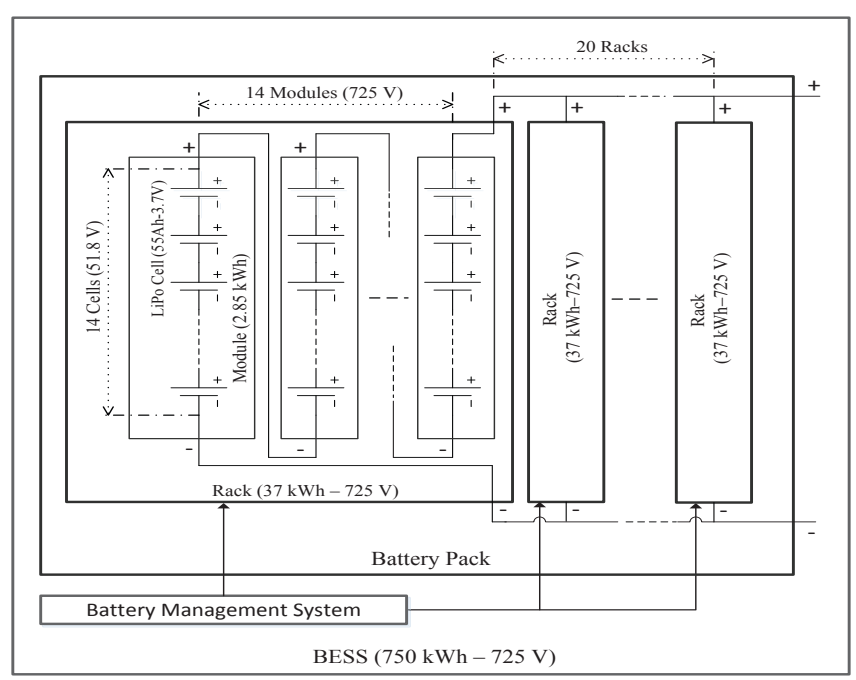

Fig. 4 Battery energy storage system architecture

The battery pack is constructed of lithium polymer (LiPo) cells. Lithium cells offer great advantageous in size and weight characteristics when compared to other battery storage technologies. Lithium cells have an average specific energy of $200 \mathrm{Wh} / \mathrm{kg}$ and an average energy density of $350 \mathrm{Wh} / \mathrm{L}$ which is more than double that of Nickel Cadmium cells for both aspects. As shown in

Fig. 4, each module is comprised of 14 LiPo cells connected in series. Fourteen 51.8 volt Modules are in turn connected in series amongst each other to form a single rack of a nominal voltage of $725 \mathrm{~V}$. The ESS is comprised of 20 of the specified racks connected in parallel. The exact specifications for cells, modules and racks forming the BESS are summarized in Table I. 


\begin{tabular}{|c|c|c|}
\hline & Parameter & Value \\
\hline \multirow{5}{*}{ Cell } & Type & Li-Polymer \\
\hline & Internal Resistance & $0.7 \mathrm{~m} \Omega$ \\
\hline & Capacity & $55 \mathrm{Ah}$ \\
\hline & Nominal Voltage & $3.7 \mathrm{~V}$ \\
\hline & Operational Voltage Range & $2.7 \mathrm{~V}-4.2 \mathrm{~V}$ \\
\hline \multirow{4}{*}{ Module } & Connection Type & Series \\
\hline & Number of Cells per Module & 14 \\
\hline & Nominal Voltage & $51.8 \mathrm{~V}$ \\
\hline & Capacity & $2.85 \mathrm{kWh}$ \\
\hline \multirow{5}{*}{ Rack } & Connection Type & Parallel \\
\hline & Number of Modules per Rack & 14 \\
\hline & Nominal Voltage & $725 \mathrm{~V}$ \\
\hline & Operational Voltage Range & $645-815 \mathrm{~V}$ \\
\hline & Capacity & $37 \mathrm{kWh}$ \\
\hline \multirow{6}{*}{$\begin{array}{c}\text { Battery } \\
\text { Pack }\end{array}$} & Connection Type & Parallel \\
\hline & Number of Racks in ESS & 20 \\
\hline & Nominal Voltage & $725 \mathrm{~V}$ \\
\hline & Operational Voltage Range & $645-815 \mathrm{~V}$ \\
\hline & Capacity & $750 \mathrm{kWh}$ \\
\hline & $\begin{array}{c}\text { Maximum Charge \& Discharge } \\
\text { Power }\end{array}$ & $250 \mathrm{~kW}$ \\
\hline
\end{tabular}

\section{PV Station}

The PV station described is connected on the same bus as that of the BESMS. As shown in Fig. 5(a), the practical system consists of six separate arrays connected to six separate inverters which are commonly connected to the PCC on their respective $\mathrm{AC}$ side. Each array utilizes different $\mathrm{PV}$ architecture. Nevertheless, $70 \%$ of the total PV station capacity is of the same module and inverter type. For evaluation purpose, the system is aggregated into a single array with a single inverter as shown in Fig. 5(b). The PV module and inverter used for the aggregated PV station array is that which is most common in the practical station. The models thus developed are then validated using practical irradiance, AC, DC voltage and active power output data.

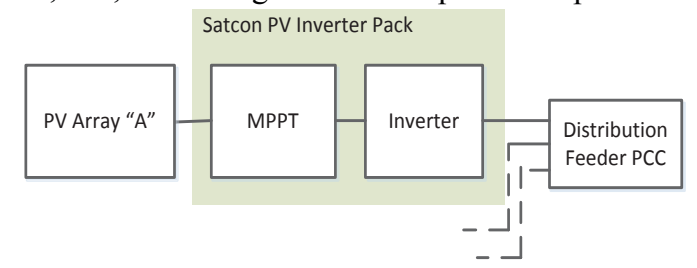

(a)

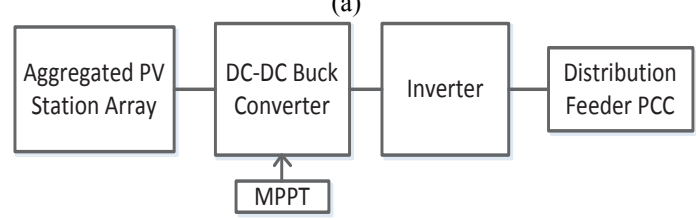

(b)

Fig. 5 PV Station. (a) Practical system. (b) Modeled system

\section{PROPOSED CONTROL METHODOLOGY AND FRAMEWORK}

The proposed control methodology relies on gathering data from different points of the described distribution feeder. These data sets are published to a message bus where data can be accessed by authorized system operators. A remote dedicated system is used to subscribe to the message bus and acquire data inputs needed for the different BESS applications implemented. The real time system data is streamed through the utility operated message bus as shown in Fig. 6. Both real time system data and recorded historical data are used to predict feeder peak load, determine optimum PV capacity firming degree and prioritize ESS functions according to anticipated value.

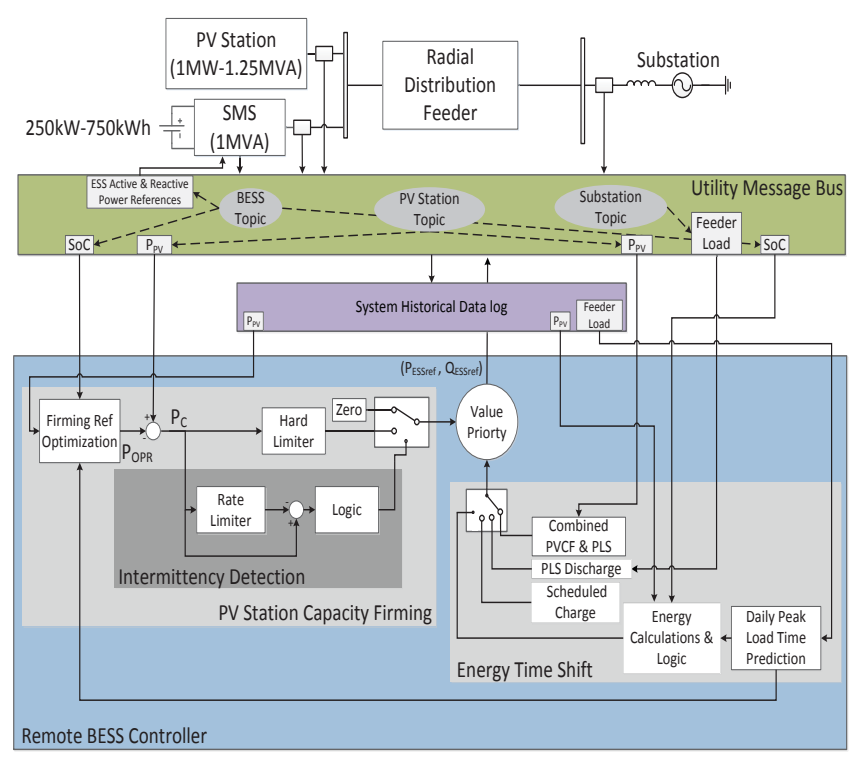

Fig. 6 Block diagram schematic for PV station capacity firming and energy time shift applications.

\section{A. PV Capacity Firming}

The BESS control algorithm for PVCF aims to minimize PV station power swings. The described PVCF algorithm targets large power swings occurring at noon when PV output is at its peak. These swings are the most crucial to minimize transients in any distribution feeder. A PV reference curve is utilized to determine the optimal PV power output during power swings. This reference curve is deduced taking into account the PV station characteristics and BESS size. The PV capacity firming algorithm depends on a four stage Adaptive Filtering Control (AFC) methodology. First, a reference power curve is developed based on daily PV power output. Second, a reference smoothing algorithm is developed that represents the changes in the power with respect to the power swings and battery capacity. Third an optimal power reference is developed that allows for maximum PV swing suppression at the peak power developed during the time of the day. Based on the AFC control architecture, further the PV intermittency is detected. The details of the algorithm are discussed next.

\section{i. Reference Power Calculation}

The PVCF algorithm uses short term historical PV station output to develop a characteristic maximum PV curve for the PV station location at that time of year. For a daily output power of PV station $P_{k}(t)$ where $k$ signifies the day; $k=$ $1,2,3,4, \ldots \ldots n$, the characteristic maximum and minimum PV curve is given by:

$$
\begin{aligned}
& P_{m}^{\max }(t)=\max \left\{P_{p v}(t), P_{p v}(t-\Delta t), ., P_{p v}(t-(n-1) \Delta t)\right\} \\
& P_{m}^{\min }(t)=\min \left\{P_{p v}(t), P_{p v}(t-\Delta t), ., P_{p v}(t-(n-1) \Delta t)\right\}
\end{aligned}
$$

Where $T=n \Delta t$ and ' $\mathrm{n}$ ' represents the number of previous days utilized to form the characteristic maximum and 
minimum PV curves. Then the reference power can be written as:-

$$
P_{m}(t)=\frac{\sum_{k=1}^{n} \mu_{k} P_{m}^{\max }(t)-\sum_{k=1}^{n} \mu_{k} P_{m}^{\min }}{\sum_{k=1}^{n} \mu_{k}}
$$

For a daily input data and to capture maximum power from the PV farm, the daily reference curve can be represented as

$$
\begin{aligned}
P_{m}(t)= & \max \left\{P_{m}(t), P_{m}(t-\Delta t), \ldots, P_{m}(t\right. \\
& -(n-1) \Delta t)\}
\end{aligned}
$$

Where ' $\mathrm{t}$ ' represents current day and $\Delta t$ represents the previous days or in a general form,

$$
P_{m}(t)=\max \left(P_{1}(t), P_{2}(t), P_{3}(t) \ldots . P_{n}(t)\right)
$$

Considering the above, the rate of power changes can be represented as

$$
r P_{m}(t)=\frac{\Delta P_{m}(t)}{\Delta t}=\frac{P_{m}(t)-P_{m}(t-\Delta t)}{\Delta t}
$$

It could be noted that (6) can be written as a function of maximum and minimum power from the PV as

$$
r P_{m}(t)=f_{P V}\left(\frac{P_{m}^{\max }(t)-P_{m}^{\min }(t)}{P_{m}(t)}\right)
$$

Let $U_{l}$ be the maximum allowed ramp rate and $L_{l}$ be the minimum allowed ramp rate then on the same token

$$
U_{l}(t)=\frac{P_{m}^{\max }(t)-P_{m}^{\max }(t-\Delta t)}{\Delta t}
$$

And,

$$
L_{l}(t)=\frac{P_{m}^{\min }(t)-P_{m}^{\min }(t-\Delta t)}{\Delta t}
$$

\section{ii. Smoothed characteristic maximum power calculation}

Let $P_{S C M P}(t)$ be the representation of the smooth characteristic reference power. Then the smooth characteristic reference power for any day or time can be represented as

$$
\begin{aligned}
& \text { Term1 Term2 } \\
& P_{S C M P}(t)=P_{S C M P}(t-\Delta t) e^{-\frac{\Delta t}{T}}+\frac{\Delta t}{T}\left(P_{m}(t)-P_{m}(t-\Delta t)\right) \\
& + \text { higher order terms }
\end{aligned}
$$

Where term 1 represents the smooth reference curve for the previous day and term 2 and higher order terms represents the rate of changes.

Ignoring higher order terms in + higher order terms (10) and noting that the smooth reference curve for previous days can be the representatives for the current $P_{m}(t)$, it can be implied that $P_{S C M P}(t-\Delta t) e^{-\Delta t / T}$ settles to $P_{m}(t-\Delta t)$ and thus without considering any optimization, the smoothed characteristic maximum power curve (SCMP) is defined as

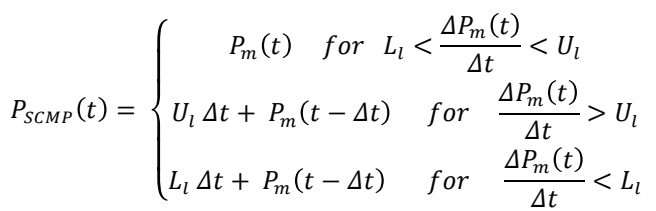

Where $\quad U_{l} \Delta t+P_{m}(t-\Delta t)=P_{m}{ }^{\max }(t)-P_{m}{ }^{\max }(t-\Delta t)+$ $P_{m}(t-\Delta t)$ and $L_{l} \Delta t+P_{m}(t-\Delta t)=P_{m}{ }^{\text {min }}(t)-P_{m}{ }^{\min }(t-\Delta t)+$ $P_{m}(t-\Delta t)$

\section{iii. Optimal reference power calculation}

As discussed the third stage is to develop an optimal reference power considering the ramp rates and the battery state of charge. The PV optimum power reference curve (OPR) is a fraction of the SCMP curve. This can be written as

$$
P_{O P R}(t)=m \times P_{S C M P}(t)
$$

The weighting factor $(m)$ is initially chosen in order to provide maximum suppression for power swings occurring at noon (peak PV power) which represent the greatest impact on the system. As it can be noticed from the previous equations, the shape of the OPR controls the degree of attainable PV capacity firming. Also, it dictates the extent to which the battery intervenes. So, we can infer that the factor ' $m$ ' can be used to control both the degree of firming and battery state of charge (SoC) at the end of the firming period. Let us calculate the value of $m$ that corresponds to maximum PV firming. Considering $R_{u}$ as the upper firming limit of the battery for a determined OPR curve

$$
\begin{aligned}
R_{u}(t) & =m P_{S C M P}(t)+P_{\text {Bmax }} \\
R_{u}\left(t_{\text {noon }}\right) & =m P_{S C M P}\left(t_{\text {noon }}\right)+P_{\text {Bmax }}
\end{aligned}
$$

Where $P_{B \max }$ is the maximum power that can be utilized from the battery at any given time. Since maximum PV power firming is attained if $R_{u}$ is equal to $P_{S C M P}$ at noon (i.e. maximum PV power time)

$$
R_{u}\left(t_{\text {noon }}\right)=P_{S C M P}\left(t_{\text {noon }}\right)
$$

Thus the required optimization factor ' $m$ ' for maximum firming can be calculated as follows

$$
m_{i}=1-\frac{P_{B \max }}{P_{S C M P}\left(t_{\text {noon }}\right)}
$$

Looking at the energy side, it is required to attain a maximum SoC at the end of the firming period (in order to have the BESS perform multiple functions. In this paper we are considering energy time shift function).

For a certain time step $(\Delta t)$,

$$
\Delta S o C \times E_{\text {Bcap }}=\left(P_{P V}-m P_{S C M P}\right) \Delta t
$$

Where $E_{B c a p}$ is the battery energy capacity, $\triangle S o C$ is the change in state of charge and $P_{P V}$ PV power output at any given time. Then the optimal weighting factor $m_{O p t}$ is

$$
\begin{gathered}
m_{O p t}=\frac{P_{P V}}{P_{S C M P}}-\frac{E_{\text {Bcap }}}{P_{S C M P}} \frac{\Delta S o C}{\Delta t} \\
\frac{\Delta S O C}{\Delta t}=\frac{S o C_{\text {targ }}-S o C}{T_{\text {targ }}-t}
\end{gathered}
$$

As shown in (18), it can be seen that the value of $m$ can be adjusted each time step $(\Delta t)$ to allow battery SoC to reach a target value $\left(S o C_{\text {targ }}\right)$ at a target time $\left(T_{\text {targ }}\right)$. For our case, our target value is $100 \% \mathrm{SoC}$ at a target time $\left(T_{P V e n d}\right)$. 


\section{iv. Intermittency Detection}

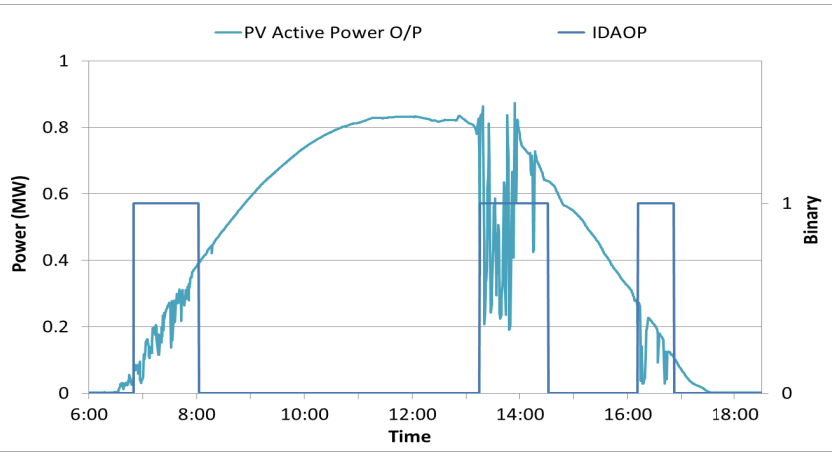

Fig. 7. Intermittency detection algorithm output

Intermittency detection allows the idling of the battery during times when PV output power is smooth and does not require conditioning. The intermittency detection algorithm relies on constantly tracking the rate of change of the difference $\left(P_{c}\right)$ between the output PV power and the OPF curve. The real time measured values of $\left(P_{c}\right)$ are passed through a rate limiter which keeps maximum rate of change of $\left(P_{c f}\right)$ less than a preset threshold. $\left(P_{c f}\right)$ is then subtracted from $\left(P_{c}\right)$ to obtain $(D)$. If the value of $D$ violates an upper or lower limit, intermittency is then assumed to be present and firming is commenced. Smoothing continues till value of $D$ is maintained within limits for a period $\mathrm{T}_{\mathrm{d}}$.

$$
\begin{gathered}
P_{c}(t)=P_{p v}(t)-P_{O P R}(t) \\
P_{c f}(t)=\left\{\begin{array}{c}
P_{c}(t) \quad \text { for } L_{l 2}<\frac{\Delta P_{c}(t)}{\Delta t}<U_{l 2} \\
U_{l} \Delta t+P_{c}(t-\Delta t) \quad \text { for } \quad \frac{\Delta P_{c}(t)}{\Delta t}>U_{l 2} \\
L_{l} \Delta t+P_{c}(t-\Delta t) \quad \text { for } \quad \frac{\Delta P_{c}(t)}{\Delta t}<L_{l 2} \\
D(t)=P_{c}(t)-P_{c f}(t)
\end{array}\right.
\end{gathered}
$$

\section{B. Energy Time Shift (ETS) Algorithm}

The ETS algorithm designed here after aims to achieve the electricity market equivalent of financial arbitrage, a term widely used by utilities and storage system operators for ETS applications. The financial definition of arbitrage is the simultaneous purchase and sale of identical commodities across two or more markets in order to benefit from a discrepancy in their price relationship. In order to efficiently achieve this, the precise prediction of peak load magnitude and time is crucial. Studying the long time interval load curves, it was found that applying a moving average prediction scheme with variable intervals provides accurate prediction. Relying on this, the algorithm checks the battery state of charge (SoC) and calculates the time of day to commence battery discharge such that the predicted load curve maximum time lies in the middle of the discharge time period.

$$
P_{\text {est }}(n+1)=\frac{\sum_{k=n-M+1}^{n} P_{k}(t)}{M}
$$

Where, $n$ represents the current day and $M$ is the moving average interval.

$$
T_{e s t}(n+1)=\frac{\sum_{k=n-M+1}^{n} T_{k}(t)}{M}
$$

$P_{k}(t)$ and $T_{k}(t)$ are the magnitude and time of daily peak loads for the $\mathrm{k}^{\text {th }}$ day, respectively.

$$
T_{\text {Dstart }}=T_{\text {Lpeak }}-\frac{(\text { SoC }) \times E_{C a p}}{2 \times P_{D}}
$$

Assuming the battery is fully charged and will perform smoothing at maximum battery capacity $(250 \mathrm{~kW})$, the total time of discharge is three hours. This covers the average prediction error calculated for mass load data. Also, since load curves of most days show minimal load at 4:30am, the PVS algorithm is set to start charging the battery at 3 am to avoid the local maximum that occurs at 7:00am.

\section{COMMUNICATION CONTROL ARCHITECTURE}

\section{A. Network Model}

In order to ensure that the data flow from battery site to the control station is adequately secure and can be reliably accessed, a reliable communication model is considered. Data originates from multiple different devices at the battery site. These devices are all connected to a local area network at the substation utilizing the DNP3 protocol. Also on the local area is an on-board computer, running a custom version of linux. This computer hosts an application that acts as a DNP3 master for these devices, issuing polls and then translating this data into messages to be published as separate topics on the message bus.

\section{IMPLEMENTATION RESULTS}

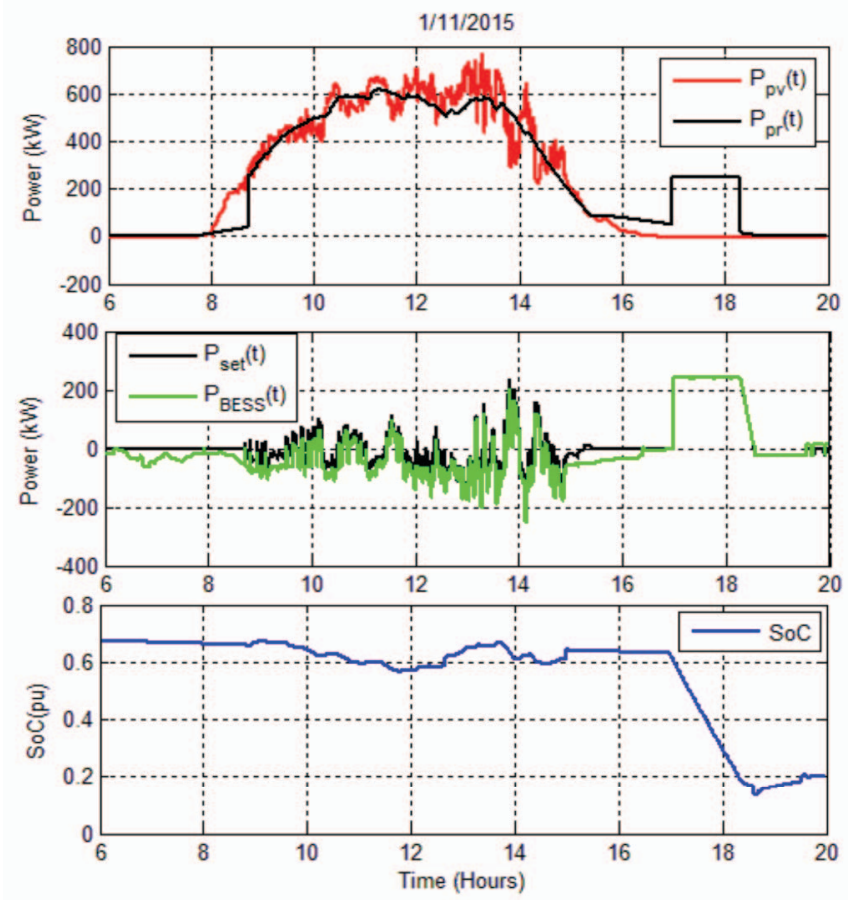

Fig. 8. PV power compared to reference power, algorithm set-point compared to actual BESS dispatched power and SoC, respectively for feeder peak load assumed to occur after firming period ends.

The designed controller simulation results are presented in [16]. After the practical implementation of the devised controller was performed using the described communication 
infrastructure, two sets of algorithm practical testing were performed. The first includes assuming that feeder peak load occurs at the end of the firming period (after sunset). The second includes assuming that feeder peak load occurs within the firming period (before sunset).

\section{A. Feeder Peak Load Occurs after firming period ends}
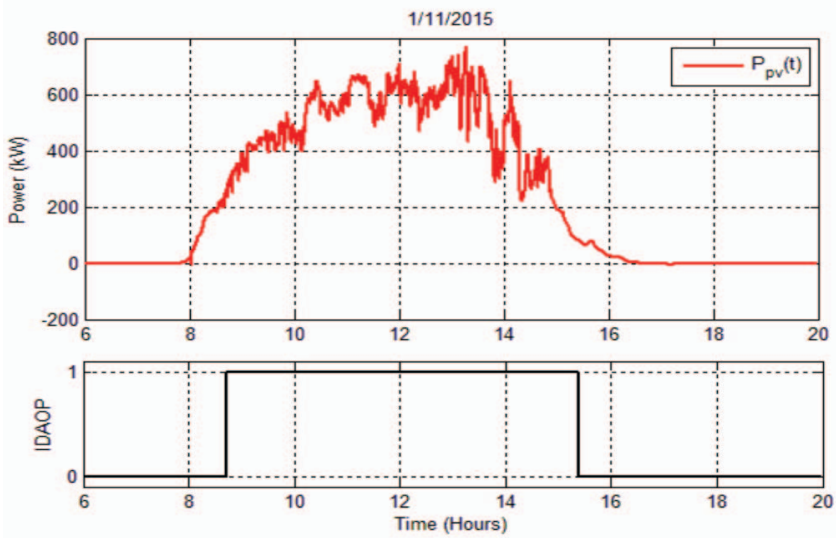

Fig. 9 Intermittency detection algorithm output for feeder peak load assumed to occur after firming period ends

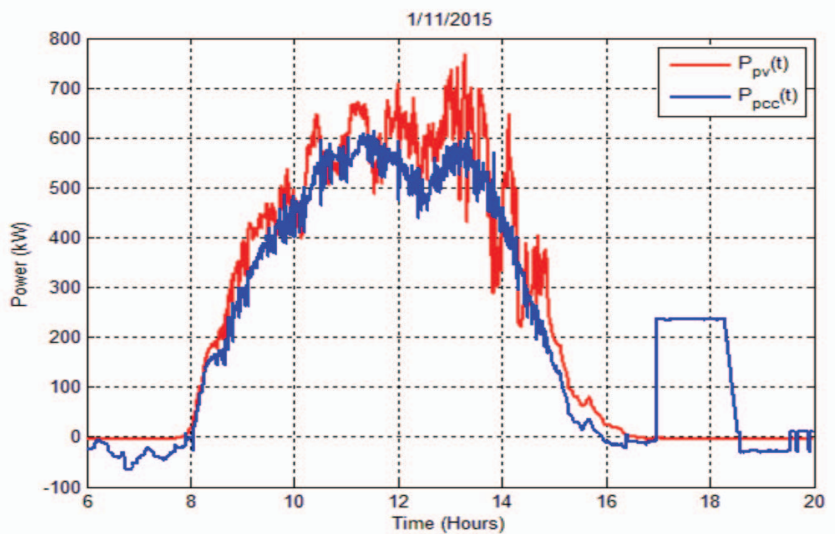

Fig. 10 PCC power preserved by the distribution feeder compared to PV station output power for feeder peak load assumed to occur after firming period ends

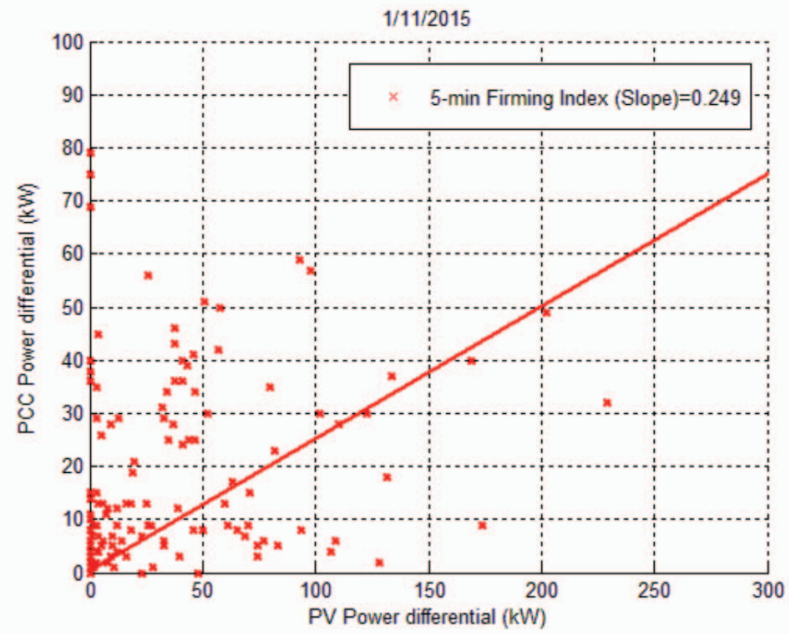

Fig. 11 Firming index for feeder peak load assumed to occur after firming period ends
In this case, modification of the discussed weighing factor $(m)$ according to $\mathrm{SoC}$ is performed over a greater time span allowing the SoC more time to be maximized or at the least, maintained throughout the firming period and thus, the SoC constraint on firming has a lesser impact. This gives better PVCF results. The practical operational characteristics in this case are presented in four figures. Fig. 8 shows the firming reference real-time variation and associated parameters, namely, SoC, active power set points $\left(P_{\text {set }}(t)\right)$, actual active power output from BESS $\left(P_{B E S S}(t)\right)$ and PV power output. It is worth mentioning that slight differences between the active power reference and the actual active power output can be attributed to the simultaneous dispatch of reactive power which practically offsets active power. Fig. 9 presents operation of the intermittency detection algorithm. Fig. 10 presents a firming index purposed to quantify the degree of firming performed. This index is similar to that applied in [24]. Further, this index is defined as the slope of the least square line of the PCC power 5-minute differential plotted against that of the PV power. In other words, each point on the plot shown in Fig. 11 has an $\mathrm{x}$-axis value equal to the PV power differential over 5 minutes and a $y$-axis value equal to the PCC power differential over the same period.

So, a point at $(200,50)$ implies that a 5 min power swing of $200 \mathrm{~kW}$ out of the PV station was reduced to $50 \mathrm{~kW}$ at the PCC, after BESS PVCF algorithm intervention. Now, taking the least square linear regression line's slope over the entire firming period gives an indication of how much firming was performed. Therefore, a unity slope implies no firming. On the other hand, a zero slope implies theoretical maximum firming. As shown, in the case of feeder peak load occurring after the firming period, considerable firming is attainable even with the SoC maximization constraint.

\section{B. Feeder Peak Load Occurs before firming period ends}

In this case, modification of $(m)$ according to SoC is performed over a shorter time span causing a greater impact from the SoC maximization constraint on firming degree. This is due to the less time allotted to reach the target SoC. However, this came with the price of intensifying power swings that occurred at $1: 30 \mathrm{pm}$ since instantaneous power reference value was at a low level compared to PV output. Figs. 12-15 shown for the case where feeder peak load is assumed to occur after the end of the firming period are presented for this case. Through these figures, it can be noticed that the value of the weighing factor $m$, which is the main factor affecting the value of $P_{p r}(t)$, is not incremented after noon since SoC value is at a relatively low level for the intended ETS application, which depends on the assumed time of feeder peak load. The reason $m$ is not incremented is that this offers a greater chance of the BESS performing PVCF while charging rather than discharging. Provided that significant power swings would occur to turn on the IDAOP, further charge firming would have taken place to further charge the BESS before the assumed feeder peak load time. Fig. 16 presents the feeder active power load compared to substation dispatched power. It is clear that prediction of time of feeder peak load by the ETS application was accurate. This resulted in a $413 \mathrm{~kW}(10.2 \%)$ reduction in peak load. 

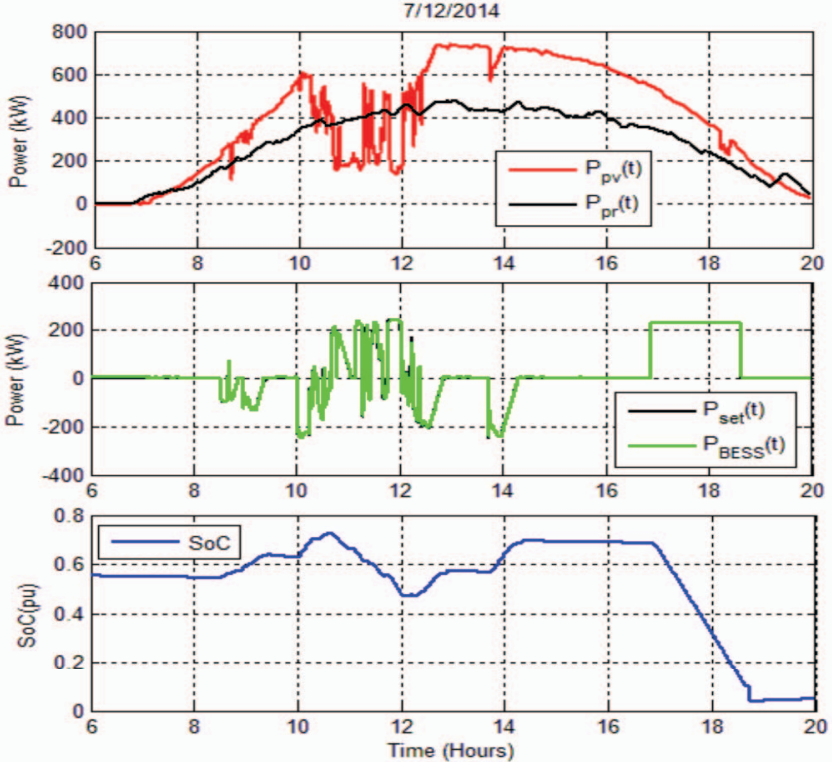

Fig. 12 PV power compared to reference power, algorithm set-point compared to actual BESS dispatched power and SoC, respectively for feeder peak load assumed to occur before firming period ends.
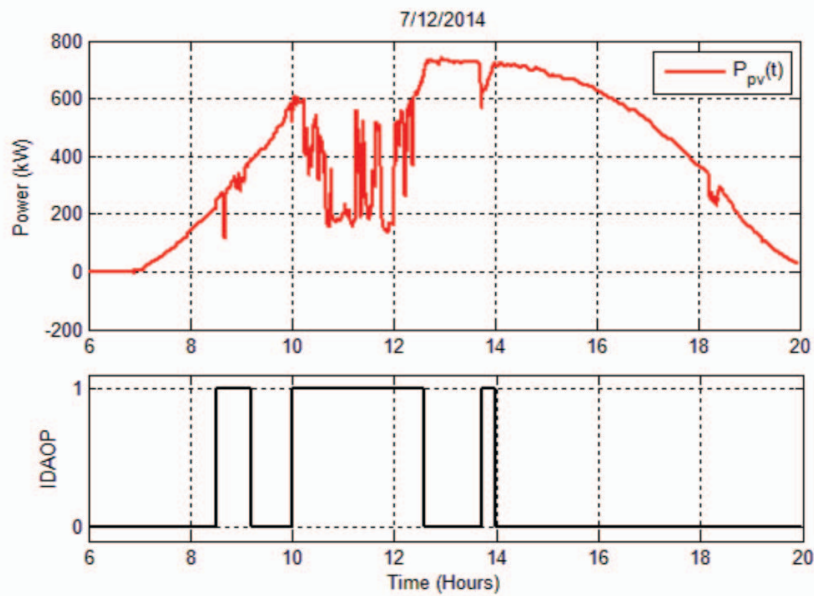

Fig. 13 Intermittency detection algorithm output for feeder peak load assumed to occur before firming period ends.

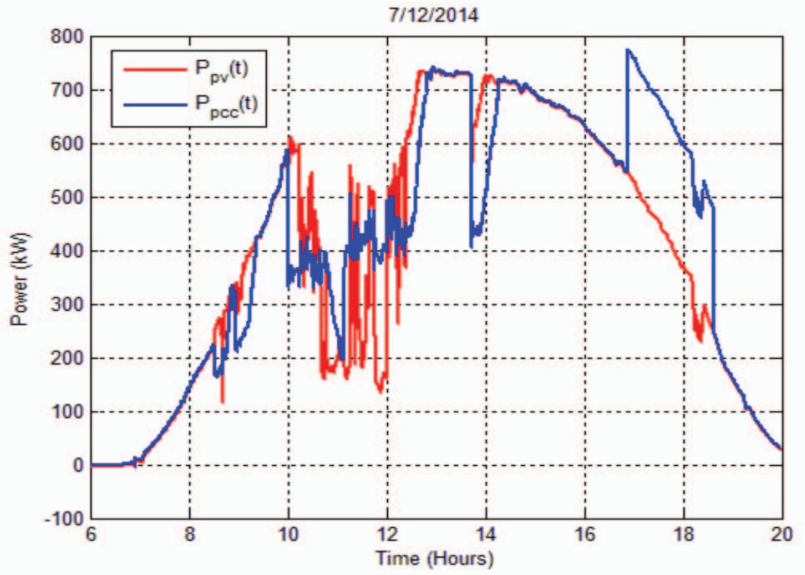

Fig. 14 PCC power preserved by the distribution feeder compared to PV station output power for feeder peak load assumed to occur before firming period ends

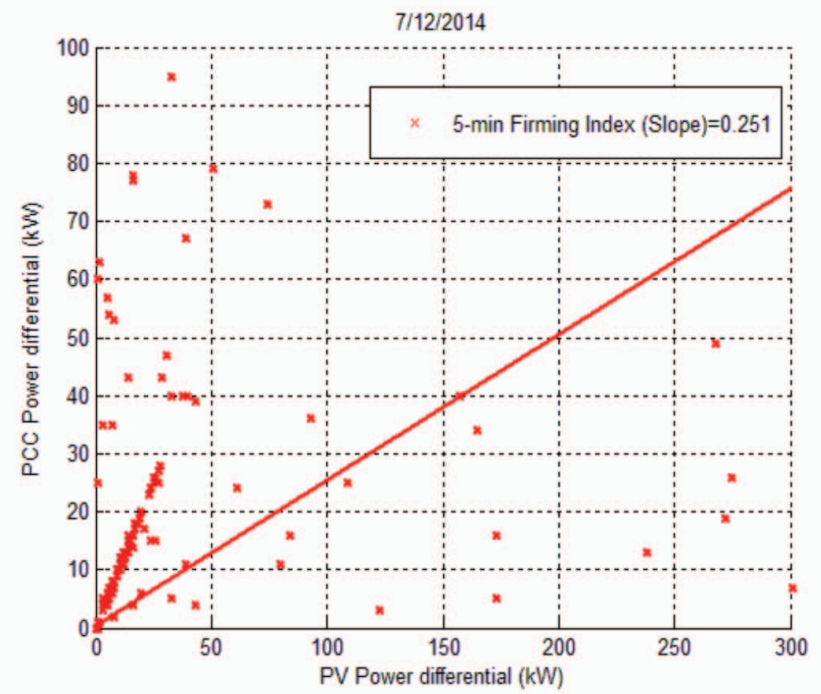

Fig. 15 Firming index for feeder peak load assumed to occur before firming period ends

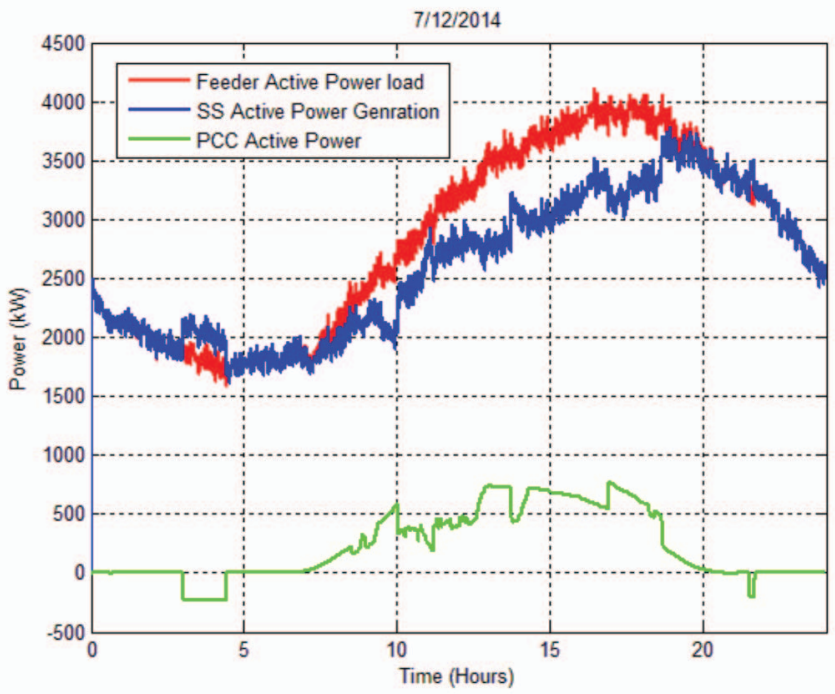

Fig. 16 Substation output power compared to feeder load showing effect of firming and ETS applications for feeder peak load assumed to occur before firming period ends.

\section{CONCluSions \& FUTURE WORK}

The results displayed lead us to conclude that the devised PVCF \& ETS applications were successful in performing their respective functions. Optimized PV firming was successful in allowing the opportunity for multiple function implementations while still performing its firming application. However, further optimization research is required in terms of optimal starting $\mathrm{SoC}$ values for both applications and weighing factor $(m)$ rate of change constraints. The ETS feeder peak load time prediction method presented valuable peak load shaving results. Communication infrastructure provided a great environment for extended testing of the devised algorithms. It was also successful in conveying 
controller inputs and outputs to and from the BESMS which allowed efficient control.

\section{REFERENCES}

[1] J. McDowall, "Conventional battery technologies-Present and future," in Proc. 2000 IEEE Power Engineering Society Summer Meeting, vol. 3, July 2000, pp. 1538-1540.

[2] W. V. Hassenzahl, Capacitors for Electric Utility Energy Storage: Electric Power Res. Inst., 1997, vol. WO-8812.

[3] R. B. Boom and H. A. Peterson, "Superconductive energy storage for power systems," IEEE Trans. Magn., vol. MAG-8, pp. 701-704, Sept. 1972.

[4] R. F. Giese, "Progress toward high temperature superconducting magnetic energy storage (SMES) systems-A second look," Argonne National Laboratory, 1998.

[5] I. D. Hassan, R. M. Bucci, and K. T. Swe, "400 MW SMES power conditioning system development and simulation," Trans. Power Electron., vol. 8, pp. 237-249, July 1993.

[6] Q. Jiang and M. F. Conlon, "The power regulation of a PWM type superconducting magnetic energy storage unit," IEEE Trans. Energy Conversion, vol. 11, pp. 168-174, Mar. 1996.

[7] W. R. Lachs and D. Sutanto, "Battery storage plant within large load centers,” IEEE Trans. Power Syst., vol. 7, pp. 762-769, May 1992.

[8] M. A. Casacca, M. R. Capobianco, and Z. M. Salameh, "Lead-acid battery storage configurations for improved available capacity," IEEE Trans. Energy Conversion, vol. 11, pp. 139-145, Mar. 1996.

[9] N.W. Miller, et.al., "Design and commissioning of a 5 MVA, $2.5 \mathrm{MWh}$ battery energy storage," in Proc. 1996 IEEE Power Engineering Society Transmission and Distribution Conf., 1996, pp. 339-345.

[10] N. Abi-Samra, C. Neft, A. Sundaram, and W. Malcolm, "The distribution system dynamic voltage restorer and its applications at industrial facilities with sensitive loads," in Proc. 8th Int. Power Quality Solutions '95, Long Beach, CA, Sept. 9-15, 1995.

[11] Grid Energy Storage, US Department of Energy Report, December 2013.

[12] Akhil, A.A., Huff, G, Currier, A.B., Kaun, B.C, Rastler, D.M., Chen, S.B., Gauntlett, W.D. , DOE/EPRI 2013 Electricity Storage Handbook in Collaboration with NRECA. Sandia National Laboratories Report, SAND2013-5131.

[13] Tremblay, O., \& Dessaint, L. (2009). Experimental Validation of a Battery Dynamic Model for EV Applications. World Electric Vehicle Journal, 3, 1-10.

[14] http://websphereknowledge.blogspot.com/2013/01/ssl-in-mq.html

[15] "What Is SSL (Secure Sockets Layer) and What Are SSL Certificates?" What Is SSL (Secure Sockets Layer)? Digicert, n.d. Web. 21 Apr. 2014. <http://www.digicert.com/ssl.htm>.

[16] Abdelrazek, S.; Kamalasadan, S., "Integrated control of battery energy storage management system considering PV capacity firming and energy time shift applications," Industry Applications Society Annual Meeting, 2014 IEEE , vol., no., pp.1,7, 5-9 Oct. 2014

[17] Kakimoto, Naoto; Satoh, H.; Takayama, S.; Nakamura, K., "Ramp-Rate Control of Photovoltaic Generator With Electric Double-Layer Capacitor," Energy Conversion, IEEE Transactions on , vol.24, no.2, pp.465,473, June 2009

[18] T. D. Hund, S. Gonzalez, and K. Barrett, "Grid-tied PV system energy smoothing," in Proc. Photovoltaic Spec. Conf., Honolulu, HI, USA, Jun. 20-25, 2010, pp. 2762-2766.

[19] S. G. Tesfahunegn, Ø. Ulleberg, P. J. Vie, and T. M. Undeland, "PV fluctuation balancing using hydrogen storage-A smoothing method for integration of PV generation into the utility grid," Energy Procedia, vol. 12, pp. 1015-1022, 2011.

[20] L. Xiangjun, H. Dong, and L. Xiaokang, "Battery energy storage station (BESS)-Based smoothing control of photovoltaic (PV) and wind power generation fluctuations," IEEE Trans. Sustainable Energy, vol. 4, no. 2, pp. 464-473, Apr. 2013.

[21] M. J. E. Alam, K. M. Muttaqi, D. Sutanto, “ A Novel Approach for Ramp-Rate Control of Solar PV Using Energy Storage to Mitigate Output Fluctuations Caused by Cloud Passing", IEEE Trans. Energy Conversion, vol. 29, No. 2, pp. 507-518, Apr. 2013.

[22] http://websphereknowledge.blogspot.com/2013/01/ssl-in-mq.html

[23] "What Is SSL (Secure Sockets Layer) and What Are SSL Certificates?" What Is SSL (Secure Sockets Layer)? Digicert, n.d. Web. 21 Apr. 2014. $<$ http://www.digicert.com/ssl.htm>.
[24] Sowder, Dan, "Mitigating solar intermittency using energy storage on a utility distribution system," Clemson University Power Systems Conference | Conference \& Exposition, 2013 IEEE , February $13^{\text {th }}, 2013$ 